\title{
Measurement of Two-dimension Justice Belief: Retribution and Balance
}

\author{
S. TAO \& C.C. YUAN \\ Institute of Applied Psychology, School of Ideological and Political Education, China University of \\ Geosciences, Beijing, China \\ Y. XU \\ School of Psychology, Beijing Normal University, Beijing, China
}

\begin{abstract}
Living in an unpredictable and uncontrollable unjust world would be unbearably threatening, so people prefer to believe that the social system is fair, legitimate, and justifiable. To explore the connotation of justice belief, several methods are used. First, 30 participants from various vocations are interviewed to clarify the concept. Second, the scale of justice belief is developed; exploratory factor analysis is conducted with 300 participants. Third, to evaluate the reliability and validity, retest, confirmatory factor analysis and scale of justice perception are conduct with 150 participants. Results show that, justice belief is composed by two dimensions, which are retribution justice belief (RJB) and balance justice belief (BJB). RJB means believing that the outcomes are fair and just. BJB means believing that the whole social system is balance. The scale presents good internal consistency, test-retest reliability, construct validity, convergent validity and discriminant validity.
\end{abstract}

KEYWORD: Justice belief; retribution justice belief; system balance justice belief; justice perception

\section{INTRODUCTION}

\subsection{Justice belief}

Living in an unpredictable, uncontrollable and capriciously unjust world would be unbearably threatening to human being, so there is a basic need to "belief in a just world" (BJW, Lerner 1980). Most of people, no matter belonging to which social level or status, will take the justice belief that the social system is fair, legitimate, and justifiable, people get what they deserve and deserve what they get.

Early researches in this field focus on: (1) the relevant variables of individual difference on justice belief (Lipkus et al. 1996); (2) the tendency to derogate victims, including oneself, as a means of restoring the justice belief (Reichle \& Schmitt 2002). Results show that people tend to attribute bad characters to low status group such as the poor. The unfortunate will be attributed to their own reason (Furnham \& Gunter 1984).

\subsection{System justification theory}

System justification theory (SJT) indicates that there is a common psychological tendency to justify and rationalize the status quo just as BJW theory. People tend to see the existing world as good, fair, legitimate and desirable. They believe themselves living in the best of all possible worlds (Kay et al.
2007). Not only people with high BJW need the existing system to be fair and legal, the low BJW ones also need to satisfy their justice belief, but with other means.

This theory includes a series of psychological process to obtain the legitimate and support, which are: sour grapes and sweet lemon rationalization, stereotyping of social groups, internalization of inequality social structure, victim-blaming and sometimes victim-enhancement (Jost et al. 2003, Kay et al. 2002). One of the most concerns is compensatory stereotypes (Jost et al. 2005), which means attributing advantaged group and disadvantaged groups compensate strengths and weaknesses separately. This concept expressed such views that no one has it all and the system is balance somehow. In the public belief, a fair social order is no single group can monopolize all the valuable things, each group has own advantage. It can create a comfortable illusion of equality. Jost et al.(2004) indicate that the strategy can meet the needs of the fairness and justice, even for low BJW ones. Compare with victim-derogate, compensatory stereotype is more likely to be accepted by society.

\subsection{The present study}

The BJW theory has strong culture western characteristics, especially the protestant work ethic, a 
typical western Christian thought. To maintain justice belief, individual consider the sufferings of victims as their deserved. But the SJT shows that compensation can also meet the need of justice. This viewpoint is more close to traditional Chinese culture. Through the ages, the Chinese are deeply affected by the harmony between Yin and Yang to reconcile things change of Taoist, trying to maintain balance of the whole world. Moreover, Confucianism emphasizes "the doctrine of the mean". The problems are more likely to see through a dialectical view, which are seeing the positive aspects of negative incident and the negative aspects of positive incident. Therefore, SJT may be more easily to understand and accept by Chinese people, and more in line with the China status quo.

The study is based on the Chinese local culture and refers to the BJW and SJT theory. The goal of present study is to explore the connotation and structure of the Chinese justice belief and develop an effective measurement of it.

\section{METHOD}

\subsection{Participants}

30 participants from various vocations were interviewed, 15 males and 15 females, average age at 32.39 \pm 8.21 .

300 college students participate in the item analysis part. 19 participants were removed because of missing values. The rest 289 participants include 135 males and 154 females, average age at $20.10 \pm 2.00$.

The Reliability and validity were obtained from 150 participants. In order to get the test-retest reliability, all the participants were chosen from the previous 289 participants. 7 participants were removed because of missing values. The rest 143 participants include 68 males and 75 females, average age at $22.15 \pm 2.40$.

\subsection{Procedure}

First, to clarify the concept and manifestation of justice belief, structured narrative interview method is used. The interviewees report their understanding of justice belief and represent 3 stories of justice and 3 stories of unjustice separately. Grounded theory of qualitative research is used to process the data. Two theoretical dimensions are extracted, which are retribution justice belief (RJB) and balance justice belief (BJB).

Second, the justice belief scale is developed. Items are selected from the existing justice belief scales, statement from interview, some traditional proverb, maxim and common saying. There are 35 items in the original version, which composited into two dimensions. 18 items describe the retribution justice and 17 items describe the system balance justice.

Third, the original version scale is conducted to 300 participants. Normal distribution test and exploratory factor analysis are used to reduce the items. According to the standard, two factors are extracted from the questionnaire, and 15 items were kept.

Fourth, another sample is used to test the reliability and validity, including Cronbach $\alpha$, testretest, confirmatory factor analysis and correlation with scale of justice perception.

\subsection{Measurements}

The 16-item Belief in a Just World (BJW) Scale (Quinn \& Crocker 1999) and 8-item Global BJW Scale (Kay \& Jost 2003) are used to fill the item pool of justice belief. They are all 7-point scale with some items reverse. In original studies, $\alpha=0.74 \&$ 0.56

The 8-item Social Justice Perception Scale (Kay \& Jost 2003) and 8-item Sense of Fairness Scale (Lipkus et al. 1996) are used to test the convergent validity and discriminant validity. The former scale measures whether individuals believe they are treated fairly; the latter scale measures whether individuals believe the country or the society is fair. They are all 7-point scale with some items reverse. In original studies, $\alpha=0.87 \& 0.89$.

\subsection{Statistics}

SPSS15.0 is used to conduct the descriptive statistics, exploratory factor analysis, correlation and reliability analysis. Amos7.0 is used to conduct the confirmatory factor analysis.

\section{RESULTS}

\subsection{Item analysis}

The descriptive statistics and normal distribution test is conducted first to get the mean value, standard deviation, skewness and kurtosis of each item. If the absolute value of skewness more than 3 or absolute value of kurtosis more than 10 , the variable is skewed distribution and should be excluded. Results show that the skewness of the items are between 0.003 to -2.779 , the kurtosis of the items are between 0.033 to 8.474 . The indexes all meet the criteria, and all the items can be seen as normal distribution.

Exploratory factor analysis is used to analyze the items. KMO value is 0.835. In Bartlett's test, $\chi 2=2802.301, d f=630, p<0.001$. The data meet the criteria for further exploratory factor analysis. The principal axis method and oblique rotation are used to detect factors. The criteria of extract factors and items are: (1) eigenvalue of factor more than 1 ; (2) 
item loading on the factor more than 0.3 ; (3) the item has strong theoretical relevance with corresponding factor.

Two factors are extracted from the scale. Analyzing the theoretical meaning and comparing to the original assumption, items are deleted successively. 15 items are retained, 7 items for retribution justice belief (RJB) and 8 for balance justice belief (BJB). Factor analysis indicated that the two factors explain $46.39 \%$ of the variance. Table 1 shows the factor loading pattern.

Table 1 The Factor loading pattern of justice belief scale

\begin{tabular}{|c|c|c|}
\hline \multirow{2}{*}{ Item code } & \multicolumn{2}{|c|}{ Factor pattern } \\
\cline { 2 - 3 } & RGB & BGB \\
\hline Item1 & 0.747 & \\
\hline Item2 & 0.691 & \\
\hline Item3 & 0.633 & \\
\hline Item4 & 0.618 & \\
\hline Item5 & 0.577 & \\
\hline Item6 & 0.561 & \\
\hline Item7 & 0.519 & \\
\hline Item8 & & 0.877 \\
\hline Item9 & & 0.716 \\
\hline Item10 & & 0.638 \\
\hline Item11 & & 0.622 \\
\hline Item12 & & 0.561 \\
\hline Item13 & & 0.517 \\
\hline Item14 & & 0.416 \\
\hline Item15 & & 0.314 \\
\hline
\end{tabular}

\subsection{Reliability}

Cronbach $\alpha$ is used to test the internal consistency. $\alpha_{\mathrm{GB}}=0.777$ (15 items), $\alpha_{\mathrm{RGB}}=0.881$ (7 items), $\alpha_{\mathrm{BGB}}=$ 0.769 (8 items). The indexes show that internal consistency reliability of justice belief scale is good. The test-retest correlation of the whole scale is 0.882 . The test-retest reliability of subscales are 0.865 of RGB and 0.893 of BGB.

\subsection{Validity}

The construct validity is verified by confirmatory factor analysis. The fit indices of two factors model are: $\chi^{2} / d f=1.566$, GFI $=0.895$, AGFI $=0.852$, IFI= 0.904, CFI $=0.900, \mathrm{RMSEA}=0.063$. Compare one factor model with two factors model, $\Delta \chi^{2}$ is significant $\left(\Delta \chi^{2}=130.806, \Delta d f=5, p<0.001\right)$.The two factors model fits optimally.

Correlation between justice belief and justice perception is conducted (see Table 2). There is moderate correlation between RGB and BGB. RGB has a strong predict effect on personal justice perception. The results show that the convergent validity and discriminant validity of justice belief are good.

Table 2 The correlation matrix of justice belief and justice perception

\begin{tabular}{|c|c|c|c|c|}
\hline & RGB & BGB & PJP & SJP \\
\hline RGB & 1 & & & \\
\hline BGB & $0.479 * *$ & 1 & & \\
\hline PJP & $0.630 * *$ & $0.417 * *$ & 1 & \\
\hline SJP & $0.490^{* *}$ & $0.237 * *$ & $0.512^{* *}$ & 1 \\
\hline
\end{tabular}

$* * p<0.001 ; \quad \mathrm{PJP}=$ personal justice perception; $\mathrm{SJP}=$ social justice perception

\section{DISCUSSION}

Both the believe in a just world theory(BJW) and system justification theory(SJT) point out that there is a basic need for human being to believe the world or system is fair and just. To meet this need, one has to hold specific justice belief. This study discussed the concept and connotation of justice belief.

Though a structuring narrative interview, both BJW and SJT can find some support in the narrative of interviewees. And there are more connotations in Chinese justice belief. A two dimensions model is proposed.

One perspective is that believing the pay and reward of everyone are equal. Where there's reek, there's heat. Each person's condition is determined by their own personality, hard working or other similar factors. One should take responsibility for his/her own situation. This perspective is similar with BJW. In China, some proverb illustrates this point, such as, one good turn deserves another, good and evil must at last have their reward, god help those who help themselves, you must reap what you have sown, et al. This perspective is named as retribution justice belief.

The other perspective is that believing the whole society is balanced. Each person, each group has its own advantages and disadvantages, has its own lucky and unlucky. This perspective is similar with SJT. In China, some proverb illustrates this point, such as, as good lost as found, nobody's perfect, the miserable man must have his defect causes the misery, every dog has its day, things will develop in the opposite direction when they become extreme, et al. This perspective is named as balance justice belief.

These two perspectives are concurrence. But the approve levels of both perspectives are varied with each individual. This leads to different means of maintain the justice perception. For example, when a teacher with high RJB and low BJB finds a student performing poor on one question in examination, he/she will assume the student hasn't study well and will underrate other questions when grading this 
student's paper. But when a teacher with high BJB and low RGB gives a student low rating on one question, he/she will relax the standards on other questions to keep the student not lag behind others too much.

Followed a standardized development procedure, Justice Belief Scale is accomplished. The reliability and validity are good enough for applying in various studies.

From the above, this study defined the concept of justice belief clearly, explored its structure and developed a useful measure tool. It's just the start of a series studies. Future study can focus on: (1) how the two dimensions affect the stereotypes towards the advantage and disadvantage groups; (2) the mechanic of how justice belief predicts justice perception.

\section{ACKNOWLEDGEMENT}

This research is supported by the Projects of Philosophy and Social Sciences Research of Beijing(Grant No. 12SHC024) and the Fundamental Research Funds for the Central Universities(Grant No. 2-9-2012-123).

\section{REFERENCES}

[1] Furnham, A. \& Gunter, B. 1984. Just world beliefs and attitudes towards the poor. British Journal of Social Psychology 23: 265-269.

[2] Jost, J. T. \& Kay, A. C. 2005. Exposure to benevolent sexism and complementary gender stereotypes: Consequences for specific and diffuse forms of system justification. Journal of Personality and Social Psychology 88: 498-509.

[3] Jost, J. T. et al. 2004. A decade of system justification theory: Accumulated evidence of conscious and unconscious bolstering of the status quo. Political Psychology 25: 881-919.

[4] Jost, J. T. et al. 2003. Social inequality and the reduction of ideological dissonance on behalf of the system: Evidence of enhanced system justification among the disadvantaged. European Journal of Social Psychology 33: 13-36.

[5] Kay, A. C. \& Jost, J. T. 2003. Complementary justice: Effects of "poor but happy" and "poor but honest" stereotype exemplars on system justification and implicit activation of the justice motive. Journal of Personality and Social Psychology 85: 823-837.

[6] Kay, A. C. et al. 2002. Sour grapes, sweet lemons, and the anticipatory rationalization of the status quo. Personality and Social Psychology Bulletin 28: 1300-1312.

[7] Kay, A. C. et al. 2007. Panglossian ideology in the service of system justification: How complementary stereotypes help us to rationalize inequality. In M. P. Zanna (Ed.), Advances in experimental social psycholog 38: 305-358.

[8] Lerner, M. J. 1980. The Belief in a Just World: A Fundamental Delusion. New York: Plenum Press.

[9] Lipkus, I. M. et al. 1996. The importance of distinguishing the belief in a just world for self versus for others: Implications for psychological well-being. Personality and Social Psychology Bulletin 22: 666-677.

[10] Quinn, D. M. \& Crocker, J. 1999. When ideology hurts: Effects of belief in the Protestant ethic and feeling overweight on the psychological well-being of women. Journal of Personality and Social Psychology 77: 402414.

[11] Reichle, B. \& Schmitt, M. 2002. Helping and rationalizing as alternative strategies for restoring the belief in a just world: Evidence from longitudinal change analyses. In M. Ross \& D. T. Miller (Eds.), the justice motive in everyday life: 127-148. Cambridge, England: Cambridge University Press. 